\title{
Characterization of Graphislactone $A$ as the Antioxidant and Free Radical-Scavenging Substance from the Culture of Cephalosporium sp. IFB-E001, an Endophytic Fungus in Trachelospermum jasminoides
}

\author{
Yong Chun Song, Wu Yang Huang, Cheng Sun, Feng Wu Wang, and Ren Xiang TaN* \\ Institute of Functional Biomolecules, State Key Laboratory of Pharmaceutical Biotechnology, Nanjing University; Nanjing \\ 210093, People's Republic of China. Received September 3, 2004; accepted November 9, 2004
}

\begin{abstract}
The extracts derived from cultures of 1626 endophytic strains harbored in Trachelospermum jasminoides were assayed for more potent antioxidant and/or free radical-scavenging agents. The free radical-scavenging assessment was carried out using l,l-diphenyl-2-picrylhydrazyl (DPPH) and hydroxyl radical assays, and the antioxidant actions on linoleic acid and human low-density lipoprotein (LDL) models. After extensive spectroscopic analyses, graphislactone $A$ was characterized as the most bioactive secondary metabolite of endophytic Cephalosporium sp. IFB-E001 with its free radical-scavenging (in a dose-dependent manner) and antioxidant activities ascertained in vitro to be stronger than those of butylated hydroxytoluene (BHT) and ascorbic acid, the two positive references coassayed in the study. From the demonstrated efficacy of graphislactone $A$ in preventing and protecting against oxidative injury, it can be predicted that this metabolite could be a potential agent in the management of oxidative damage-initiated diseases.
\end{abstract}

Key words endophyte; Cephalosporium sp. IFB-E001; Trachelospermum jasminoides; graphislactone A; antioxidant; free radical

There is increasing evidence indicating that reactive oxygen species (ROS, e.g., $\mathrm{O}^{2-}$ and $\mathrm{OH}^{-}$) and free radical-meditated reactions are involved in degenerative or pathologic events such as aging, cancer, coronary heart disease, and Alzheimer's disease. ${ }^{1)}$ Antioxidants are thought to be beneficial and/or curative in the management of ROS-mediated tissue injury. ${ }^{2)}$ However, only a few antioxidants have been approved to date for clinical application due to the low efficacy and/or severe side effects. Therefore there is an urgent need to search for new and more effective antioxidants with negligible or acceptable adverse effects.

Endophytes are bacteria or fungi that spend the whole or part of their lifespan inside the healthy tissues of the host inter- and/or intracellularly without causing discernible symptoms of plant disease. ${ }^{3)}$ In addition to the interest of ecologists in the relationship between endophytes and hosts, chemists and biologists are investigating the chemistry and bioactivity of endophyte metabolites. ${ }^{4)}$ The evergreen vine Trachelospermum jasminoides (LiNDL.) LEM. (Apocynaceae) has been utilized since ancient times in traditional Chinese medical practice for the treatment of rheumatic arthralgia, aching of the loins and knees, and traumatic injuries ${ }^{5)}$ and its antiinflammatory fractions have been determined. ${ }^{6}$ However, little is known about endophytes harbored inside the healthy tissues of the climbing plant. As a follow-up to our previous studies aimed at characterizing antioxidant and free radicalscavenging substances from a higher plant ${ }^{7}$ and marine microbe ${ }^{8)}$ we have isolated a total of 1626 endophytic strains from November (2001), April, and June (2002) collections of the T. jasminoides growing in the eastern suburbs of Nanjing. The subsequent screening of the $\mathrm{CHCl}_{3}: \mathrm{MeOH}(\mathrm{v} / \mathrm{v} 1: 1)$ extracts of the corresponding endophyte cultures for antioxidant and free radical-scavenging activity revealed that the most substantially active substance(s) was afforded by the endophytic fungus Cephalosporium sp. IFB-E001 residing in the roots of the November collection of T. jasminoides. We report here the full characterization of the most bioactive secondary metabolite, graphislactone A, with its free radical- scavenging and antioxidant activities confirmed in vitro to be greater than those of butylated hydroxytoluene (BHT) and ascorbic acid, the two positive references coassayed in the study.

\section{MATERIALS AND METHODS}

General EI-MS were recorded on a VG-ZAB-HS mass spectrometer and ${ }^{1} \mathrm{H}$ - and ${ }^{13} \mathrm{C}-\mathrm{NMR}$ experiments were performed on a Bruker DRX-500 NMR spectrometer using TMS as an internal standard. Silica gel $(200-300$ mesh) for column chromatography and silica $\mathrm{GF}_{254}(10-20 \mathrm{~mm})$ for TLC were products of Qingdao Marine Chemical Factory, China. Sephadex LH-20 was from Pharmacia Biotech, Sweden. All chemicals used in the study were of analytical grade.

Materials Following the procedure detailed elsewhere, ${ }^{9}$ a total of 1626 cultivable endophytic fungal isolates were obtained from the surface-sterilized fresh tissues of apparently healthy wild vines of $T$. jasminoides after collection in November (2001), April, and June (2002) from the eastern suburbs of Nanjing, China. The endophytic fungus IFB-E001 affording the most antioxidant and free radical-scavenging culture extract, was then identified as Cephalosporium sp. by comparing the morphologic characteristics and the pattern of sporulation, which are nearly identical to those described elsewhere. ${ }^{10)}$

Samples of a 5-d fresh mycelium of the fungus grown on PDA medium (potato, $200 \mathrm{~g}$; dextrose, $20 \mathrm{~g}$; agar, $20 \mathrm{~g} ; \mathrm{H}_{2} \mathrm{O}$, $1000 \mathrm{ml}$ ) in a Petri dish at $28^{\circ} \mathrm{C}$ were inoculated into 1000 $\mathrm{ml}$ Erlenmeyer flasks containing $400 \mathrm{ml}$ PD broth medium, followed by shaking $(150 \mathrm{rpm})$ continuously for $4 \mathrm{~d}$ at $28 \pm 1{ }^{\circ} \mathrm{C}$. The culture liquor $(20 \mathrm{ml})$ of the endophyte Cephalosporium sp. IFB-E001 was applied to solid-matrix steady fermentation using millet medium (millet $7.5 \mathrm{~g}$, bran $7.5 \mathrm{~g}$, yeast extract $0.5 \mathrm{~g}, \mathrm{FeSO}_{4} 0.01 \mathrm{~g}$, tartrate sodium $0.1 \mathrm{~g}$, glutamine sodium $0.1 \mathrm{~g}$ and pure corn oil $0.1 \mathrm{ml}$ in tap water $15 \mathrm{ml}$ per bottle). The fermentation, accomplished in a total of 420 bottles, was subsequently accomplished by standing 
for another $30 \mathrm{~d}$ at $28 \pm 1{ }^{\circ} \mathrm{C}$.

Extraction and Isolation The dried powdered mycelia were extracted four times with $\mathrm{CHCl}_{3}: \mathrm{MeOH}(\mathrm{v} / \mathrm{v}, 1: 1)$ at room temperature. Evaporation of the solvent in vacuo afforded $750 \mathrm{~g}$ of a dark-brownish residue. The crude extract was dissolved in a smaller amount of $\mathrm{MeOH}$ at around $45^{\circ} \mathrm{C}$ and the solution was kept at $-20^{\circ} \mathrm{C}$ overnight, followed by filtration to eliminate waxy substances as the precipitate. Removal of $\mathrm{MeOH}$ under reduced pressure gave a brown lump, to which $\mathrm{MeOH}$ was added until it dissolved completely. To the $\mathrm{MeOH}$ solution, acetone was added drop by drop with acetone $15 \%(\mathrm{v} / \mathrm{v})$, and the mixture was kept less than $-20^{\circ} \mathrm{C}$ overnight to precipitate salts and saccharides. The filtrate was concentrated in vacuo to give a residue $(250 \mathrm{~g})$, which was subjected to column chromatography on silica gel $(2000 \mathrm{~g}, 200-300 \mathrm{mesh})$ eluted with a gradient of $\mathrm{CHCl}_{3}: \mathrm{MeOH}(\mathrm{v} / \mathrm{v}, 1: 0 \rightarrow 0: 1)$ to give nine fractions (T1, $5.5 \mathrm{~g}$; T2, $21.4 \mathrm{~g}$; T3, $7.3 \mathrm{~g}$; T4, $15.6 \mathrm{~g}$; T5, $18.9 \mathrm{~g}$; T6, $24.7 \mathrm{~g}$; T7, $21.2 \mathrm{~g}$; T8, 14.1 g; T9, 69.8 g) based on TLC monitoring. Fraction T2, the most bioactive fraction, was then chromatographed on silica gel $(500 \mathrm{~g}, 200-300$ mesh $)$ using a stepwise gradient of $\mathrm{CHCl}_{3}: \mathrm{MeOH}(\mathrm{v} / \mathrm{v}, 1: 0 \rightarrow 10: 1)$ and four fractions (T21, 4.9 g; T22, $5.7 \mathrm{~g}$; T23, 7.4 g; T24, $3.8 \mathrm{~g}$ ) were obtained. T23, the bioactive fraction, was further chromatographed on silica gel (150 g, 200-300 mesh), followed by gel filtration on a Sephadex LH-20 column eluted with $\mathrm{CHCl}_{3}: \mathrm{MeOH}(\mathrm{v} / \mathrm{v}, 1: 1)$ to yield $13 \mathrm{mg}$ of yellowish powdered graphislactone A (Fig. 1) and its spectral data (EI-MS, ${ }^{1} \mathrm{H}$ - and ${ }^{13} \mathrm{C}-\mathrm{NMR}$, see above) were identical to those reported by Tanahashi et al. ${ }^{11)}$

Scavenging Activity against DPPH Radicals The scavenging activity of graphislactone A against 1,1-diphenyl-2picrylhydrazyl (DPPH) radicals was measured according to the method of Hou et al. ${ }^{12)}$ Sample solution $0.3 \mathrm{ml}$ with test amounts $(1,2,3,4,5 \mu \mathrm{g})$ of graphislactone A was added to $0.1 \mathrm{ml}$ of $1 \mathrm{M}$ Tris- $\mathrm{HCl}$ (pH 7.9), and then mixed with $0.6 \mathrm{ml}$ of DPPH $100 \mu \mathrm{M}$ in methanol for $20 \mathrm{~min}$ under protection from light at room temperature. The absorbance at $517 \mathrm{~nm}$ was measured. Deionized water was used as a blank experiment, and BHT as a positive control.

Scavenging Activity against Metal Ion-Dependent Hydroxyl Radicals The hydroxyl radicals were determined using the deoxyribose method described previously. ${ }^{12)}$ Sample solution $0.5 \mathrm{ml}$ with one of the test amounts $(0.075$, $0.165,0.24,0.315,0.405 \mu \mathrm{g})$ of graphislactone A was added to $1.0 \mathrm{ml}$ of a solution of potassium phosphate buffer $20 \mathrm{mM}$ (pH 7.4), 2-deoxy-ribose $2.8 \mathrm{~mm}$, EDTA $104 \mu \mathrm{M}, \mathrm{FeCl}_{3}$ $100 \mu \mathrm{M}$, ascorbate $100 \mu \mathrm{M}$ and hydrogen peroxide $1 \mathrm{~mm}$. The mixtures were incubated at $37^{\circ} \mathrm{C}$ for $1 \mathrm{~h}$. After incubation, an equal volume of $0.5 \%$ thiobarbituric acid in $10 \%$ trichloroacetic acid was added and the mixtures were boiled at $100^{\circ} \mathrm{C}$ for $15 \mathrm{~min}$. Deionized water was used as a blank experiment, and BHT as a positive reference. The absorbance

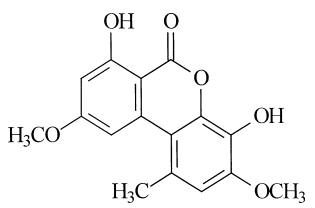

Fig. 1. Structure of Graphislactone A at the wavelength of $532 \mathrm{~nm}$ was measured.

Antioxidant Activity against Linoleic Acid Peroxidation The antiperoxidation activity of graphislactone A against $20 \mathrm{~mm}$ of linoleic acid emulsion was measured at intervals after reactions at $37^{\circ} \mathrm{C}$ using the thiocyanate method. ${ }^{13)}$ During incubation, a $0.1-\mathrm{ml}$ aliquot of the reaction mixture contain graphislactone A $50 \mu \mathrm{g}$ was mixed with $4.7 \mathrm{ml}$ of $75 \%$ ethanol, $0.1 \mathrm{ml}$ of $30 \%$ ammonium thiocyanate, and $0.1 \mathrm{ml}$ of $20 \mathrm{~mm}$ ferrous chloride in 3.5\% hydrochloric acid. Precisely $3 \mathrm{~min}$ after the addition of ferrous chloride to the reaction mixture, the absorbance at the wavelength of $500 \mathrm{~nm}$ was determined. Deionized water was used as a blank experiment, and ascorbic acid $0.5 \mathrm{mg}$ as a positive control. Increased absorbance at $500 \mathrm{~nm}$ of the reaction mixture indicates a decrease in antioxidant activity against linoleic acid peroxidation.

Protection aganist $\mathrm{Cu}^{2+}$-Induced Low-Density Lipoprotein Peroxidation EDTA in the purchased lowdensity lipoprotein (LDL) was removed prior to the peroxidation experiment, as described elsewhere. ${ }^{14)}$ The commercial LDL solution was dialyzed three times against a 500fold volume of phosphate buffer $10 \mathrm{~mm}(\mathrm{pH} 7.4$, containing $\mathrm{NaCl} 0.16 \mathrm{~mm}$ ). The capacity of graphislactone A to protect against $\mathrm{Cu}^{2+}$-induced human LDL oxidation in a total $1.1-\mathrm{ml}$ sample volume was measured in the thiobarbituric acid-reactive substance (TBARS) assay at $\left.532 \mathrm{~nm} .{ }^{15}\right) \mathrm{LDL}(0.5 \mathrm{mg}$ protein $\mathrm{ml}^{-1}$ ) was incubated at $37^{\circ} \mathrm{C}$ under air in phosphate buffer $10 \mathrm{~mm}\left(\mathrm{pH} 7.4\right.$ ) containing $\mathrm{CuSO}_{4} 10 \mu \mathrm{M}$ for $24 \mathrm{~h}$ with or without graphislactone A. The peroxidation reaction was stopped by adding EDTA $100 \mu \mathrm{M}$. The TBARS value of 24-h LDL peroxidation was assumed to be $100 \%$. BHT was utilized as a positive control.

Statistical Analysis Experimental values are expressed as mean \pm S.D. of triplicate experiments, as indicated in the legends. Student's $t$-test was used for comparison between two treatments, and a $p$ value $<0.01$ was considered statistically significant.

\section{RESULTS}

Scavenging Activities of Graphislactone A against DPPH Radicals The effects of graphislactone $A$ at the test concentrations on the scavenging of DPPH radicals was determined spectrophotometrically. As demonstrated in Fig. 2, the more graphislactone $\mathrm{A}$ added, the higher the DPPH-scavenging activities. The $\mathrm{IC}_{50}$ value of graphislactone A for DPPH radicals was $2.9 \mu \mathrm{g} \mathrm{ml}^{-1}$ (viz., 9.6 $\mu \mathrm{M}$ ), which was more potent than that of $\mathrm{BHT}\left(\mathrm{IC}_{50}, 3.2 \mu \mathrm{g} \mathrm{ml}^{-1}\right.$; viz., $19.5 \mu \mathrm{M})$, the positive control employed in this experiment.

Scavenging Activities of Graphislactone A against Metal Ion-Dependent Hydroxyl Radicals The effects of graphislactone A on the scavenging of hydroxyl radicals are shown in Fig. 3. Graphislactone A exhibited dose-dependent hydroxyl radical-scavenging activities at the test concentrations used. The effects of BHT against hydroxyl radicals were less than those of graphislactone A. The scavenging activity of graphislactone A against hydroxyl radicals was $70 \%$ and $91 \%$ at 0.05 and $0.27 \mu \mathrm{g} \mathrm{ml}^{-1}$, respectively.

Antioxidant Activity of Graphislactone A against Linoleic Acid Peroxidation As illustrated in Fig. 4, graphislactone A retarded linoleic acid peroxidation during the inter- 


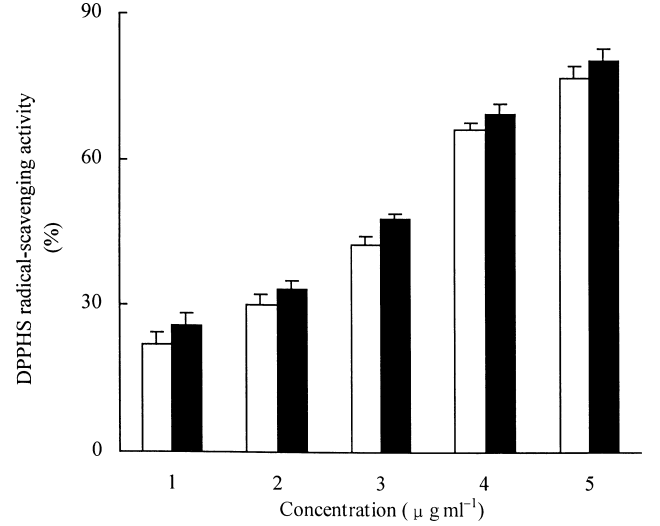

Fig. 2. Scavenging Activities of Graphislactone A ( $\mathbf{\square})$ at 1, 2, 3, 4, and $5 \mu \mathrm{g} \mathrm{ml}^{-1}$ against DPPH Radicals

BHT ( $\square$ ) served as positive control. The DPPH radical-scavenging activity (\%) was calculated using the following equation: $\left[\left(\mathrm{A}_{517}\right.\right.$ of blank $-\mathrm{A}_{517}$ of sample $) / \mathrm{A}_{517}$ of blank] $\times 100$.

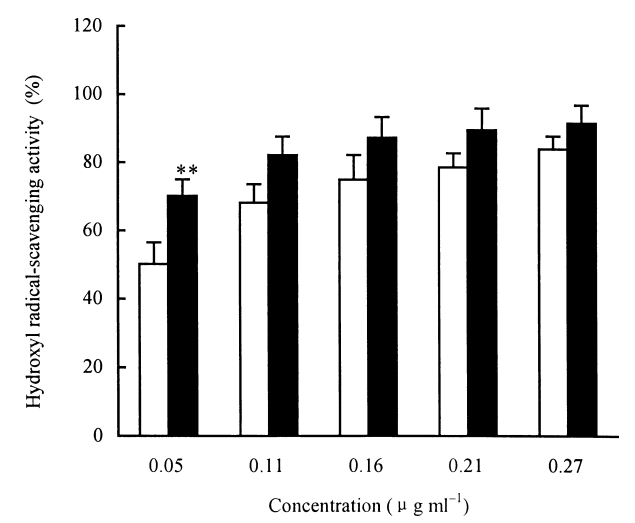

Fig. 3. Hydroxyl Radical-Scavenging Activities of Graphislactone A (ם) at Different Concentrations

BHT ( $\square$ ) served as a positive control. The hydroxyl radical-scavenging activity (\%) was calculated using the following equation: $\left[\left(\mathrm{A}_{532}\right.\right.$ of blank $-\mathrm{A}_{532}$ of sample $) / \mathrm{A}_{532}$ of blank $\times 100$. A difference was considered statistically significant when $p<0.01(* *) v s$. positive control.

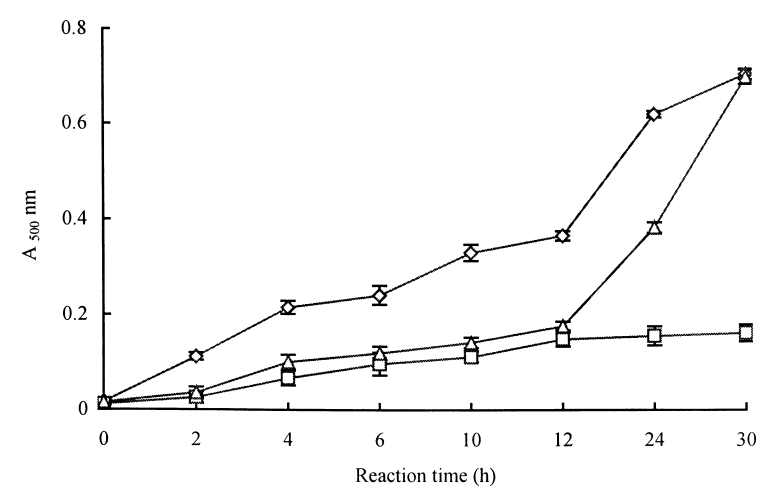

Fig. 4. Determination of the Antioxidant Activity of Graphislactone A ( $\square$ ) against Linoleic Acid Peroxidation Reactions during the Interval of $30 \mathrm{~h}$ at $37^{\circ} \mathrm{C}$ Using the Thiocyanate Method

Deionized water $(\diamond)$ was used as a blank. Ascorbic acid $(\triangle)(0.5 \mathrm{mg})$ served as a positive control.

val of $30 \mathrm{~h}$ at $37^{\circ} \mathrm{C}$ compared with the blank. Within the first $12 \mathrm{~h}$ of reaction, the positive control, ascorbic acid, showed antioxidant activity against linoleic acid peroxidation similar to that of graphislactone A. However, in the case of ascorbic

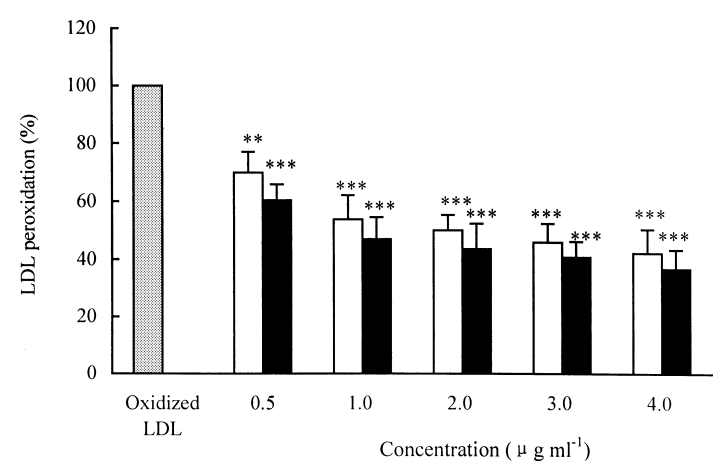

Fig. 5. Protective Effects of Graphislactone $\mathrm{A}(\mathbf{\square})$ against $\mathrm{Cu}^{2+}$-Induced Human LDL Peroxidation Using the TBARS Assay with BHT ( $\square$ ) as a Positive Control

The TBARS formed after 24-h LDL peroxidation was considered to be $100 \%$. Student's $t$-test was used for the comparison of the oxidized LDL with the other treatments. A difference was considered statistically significant when $p<0.01(* *)$ or $p<0.001(* * *) v s$. blank control.

acid, a drastic increase in linoleic acid peroxidation was found, similar to that of the blank, $30 \mathrm{~h}$ after the reaction, indicating that ascorbic acid $0.5 \mathrm{mg}$ was nearly depleted after 30 -h reaction, whereas graphislactone A retained the ability to delay lipid peroxidation. There was a 4.4-fold retardation of linoleic acid peroxidation in samples containing graphislactone A compared with those containing the blank at the end of the 30-h reaction.

Protection against $\mathrm{Cu}^{2+}$-Induced LDL Peroxidation Relative to the blank control, an approximately 17 -fold increase in LDL lipid peroxidation was induced by the presence of $\mathrm{Cu}^{2+}$. The presence of graphislactone A significantly inhibited lipid peroxidation in human LDL in a dose-dependent manner (Fig. 5). At $4 \mu \mathrm{g} \mathrm{ml}^{-1}$, the protective activity of graphislactone A was up to $62 \%$. The $\mathrm{IC}_{50}$ of graphislactone A for the protection aganist LDL peroxidation was $2.2 \mu \mathrm{g}$ $\mathrm{ml}^{-1}(7.3 \mu \mathrm{M})$, whereas the $\mathrm{IC}_{50}$ of BHT was $3.4 \mu \mathrm{g} \mathrm{ml}^{-1}$ $(20.7 \mu \mathrm{M})$. Therefore graphislactone $\mathrm{A}$ is more active than BHT.

\section{DISCUSSION}

As a relatively untapped reservoir of bioresources, some endophytic microorganisms have been demonstrated to be excellent producers of biologically active and/or structurally novel metabolites. ${ }^{16)}$ In this study, we found that the phenolic fungal metabolite graphislactone A exhibited strong free radical-scavenging and antioxidant activities using in vitro assays. This compound was previously reported as a metabolite of the lichen mycobiont Graphis spp. ${ }^{11,17)}$

The DPPH radical model system is widely used to investigate the scavenging activities of natural compounds. ${ }^{8,14)}$ In the present study, graphislactone A exhibited stronger radical-scavenging activity against DPPH radicals than did the positive control BHT (Fig. 2). In addition to DPPH radicals, hydroxyl radicals are considered to be potent oxidants, which can react with all biomacromolecules functioning in living cells. ${ }^{18)}$ In the present study, the deoxyribose assay was employed to evaluate the hydroxyl radical-scavenging activity of graphislactone A. Graphislactone A showed a pronounced activity in eliminating hydroxyl radicals in a dose-dependent manner, which was greater than that of BHT (Fig. 3). These 
results suggest that graphislactone A may attenuate the process of metal ion-dependent hydroxyl radical formation and thus reduce hydroxyl radical-induced cell injury.

The products of lipid peroxidation (such as malondialdehyde) can damage proteins and DNA. ${ }^{19)}$ In the antioxidant assay performed using the linoleic acid peroxidation model, graphislactone A was found to be more antioxidant than ascorbic acid (Fig. 4). The oxidation of LDL has been found to be associated with foam cell formation and atherosclerosis development, ${ }^{20)}$ and more recent studies have revealed that the ultimate atherogenic agents are modified (mainly oxidized) forms of LDL. ${ }^{21)}$ We therefore performed human LDL oxidation using $\mathrm{Cu}^{2+}$ as the oxidative initiator to confirm the antioxidant activity of graphislactone A. Under our experimental conditions, graphislactone A significantly suppressed TBARS formation in LDL oxidation induced by $\mathrm{Cu}^{2+}$ (Fig. 5). Therefore the phenolic fungal metabolite graphislactone A may be a potential agent to prevent LDL oxidation in vivo and in the management of atherosclerosis.

Acknowledgments The work was supported by the Ministry of Education (Key Project No.104195), National Natural Science Foundation (30300007), and by Jiangsu Natural Science Foundation (BK2003410).

\section{REFERENCES}

1) Finkel T., Holbrook N. J., Nature (London), 408, 239-247 (2000).

2) Cozma L. S., Curr. Opin. Lipidol., 15, 369-371 (2004).

3) Zou W. X., Tan R. X., Acta Bot. Sin., 43, 881-892 (2001).

4) Ji L. L., Song Y. C., Tan R. X., J. Appl. Microbiol., 96, 352-358
(2004).

5) Tu G. S., Fang Q. Z., Yuan S. C., "Pharmacopoeia of the People's Republic of China," Guangdong Science and Technology Press, Guangzhou, 1992, pp. 18-21.

6) Li R. W., Lin G. D., Myers S. P., Leach D. N., J. Ethnopharmacol., 85, $61-67$ (2003).

7) Wang J. N., Hano Y., Normura T., Chen Y. J., Tan R. X., Acta Pharm. Sin., 21, 633-636 (2000).

8) Sun C., Wang J. W., Fang L., Gao X. D., Tan R. X., Life Sci., 200, $112-118$ (2004).

9) Schulz B., Wanke U., Draeger S., Aust H. J., Mycol. Res., 97, 14471450 (1993).

10) Wei J. C., "Handbook of Identification of Fungi," Shanghai Science \& Technology Press, Shanghai, 1979, p. 495.

11) Tanahashi T., Kuroishi M., Kuwahara A., Nagakura N., Hamada N., Chem. Pharm. Bull., 45, 1183-1185 (1997).

12) Hou W. C., Hsu F. L., Lee M. H., Planta Med., 68, 1072-1076 (2002).

13) Pham T. Q., Cormier F., Farnworth E., Tong V. H., Calsteren M. V., J. Agric. Food Chem., 48, 1455-1461 (2000).

14) Katapodis P., Vardakou M., Kalogeris E., Kekos D., Macris B. J., Christakopoulos P., Eur. J. Nutr., 42, 55-60 (2003).

15) Yan L. J., Droy-Lefaix T., Packer L., Biochem. Biophys. Res. Commun., 212, 360-366 (1995).

16) Tan R. X., Zou W. X., Nat. Prod. Rep., 18, 448-459 (2001).

17) Tanahashi T., Takenaka Y., Nagakura N., Hamada, N., Phytochemistry, 62, 71-75 (2003).

18) Halliwell B., Gutteridge J. M. C., Aruoma O. I., Anal. Biochem., 165, 215-219 (1987).

19) Esterbauer H., Schaur R. G., Zollner H., Free Radic. Biol. Med., 11, 81-128 (1991).

20) Steinberg D., Parthasaranthy S., Karew T. E., Khoo J. C., Witztum J. L., N. Engl. J. Med., 320, 915-924 (1989).

21) Tribble D. L., van den Berg J. J. M., Motchnik P. M., Ames B. N., Lewis D. M., Chait A., Krauss R. M., Proc. Natl. Acad. Sci. U.S.A., 91, 1183-1187 (1994). 